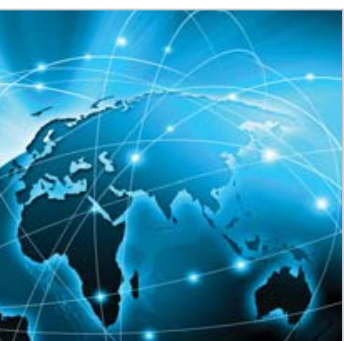

\title{
The global challenges of infectious diseases
}

\author{
Antimicrobial resistance, infection control, outbreak containment, vaccine development \\ and diagnostic advances: adapting to a changing world
}

n 2012, on behalf of the Australasian Society for Infectious Diseases (ASID), we reported in the Journal on the infectious diseases challenges for Australia in the coming decade. ${ }^{1}$ We identified antimicrobial resistance (AMR) as a public health crisis requiring global professional and political action, and reflected on how the spread of infectious diseases and AMR is affected by interconnected factors including mass transportation, climate change, environmental perturbations and mass food production. We also noted how enhanced molecular capabilities in therapeutics and diagnostics provide new opportunities for detection and containment.

\section{"Just over 12 months ago, no one could have foreseen the global ramifications of the Ebola virus epidemic"}

In this article, we take stock on the progress and changes in the global landscape since our previous report.

The past 3 years have seen increased global recognition of AMR. An ambitious strategy has been launched by the World Health Organization, which convened a ministerial conference on antibiotic resistance in June 2014 and published a draft global action plan. ${ }^{2}$ Government policies for combating AMR have also been developed in 2014, such as the national strategy in the United States ${ }^{3}$ and the 5 -year plan in the United Kingdom. ${ }^{4}$ These provide blueprints for action, as shown by the inclusion of $\$ 1.2$ billion funding for AMR in the 2016 US budget.

The Australian Government has also provided international leadership by taking a strong One Health approach to its national AMR strategy. It has established a highlevel steering group chaired jointly by the heads of the Department of Health and Department of Agriculture, supported by the Australian Strategic and Technical Advisory Group on AMR, which has highlighted the need for data on antibiotic usage and resistance to increase understanding of the drivers of AMR. ${ }^{5}$ The Australian Commission on Safety and Quality in Health Care (ACSQHC) is setting up comprehensive surveillance of AMR and consumption through the Antimicrobial Use and Resistance in Australia project, ${ }^{6}$ and a similar exercise is planned for animals and agriculture. ${ }^{7}$

One way to measure success of programs to limit AMR is through reduction of health care-associated infections (HAIs). The annual costs of HAIs in the US alone have been estimated at $\$ 23$ billion, with 115000 deaths per year. ${ }^{8}$ In Australia, the ACSQHC has been instrumental in efforts to reduce HAIs, largely via hospital accreditation.
The ACSQHC has championed hand hygiene initiatives, national infection control standards and mandatory antimicrobial stewardship programs in all Australian hospitals. These efforts promise significant benefits, as shown by a recent report of a significant reduction of Staphylococcus aureus bloodstream infections in Australian institutions. ${ }^{9}$

Despite the advances in combating AMR, we remain vulnerable to outbreaks. In his Natural history, Pliny the Elder (23-79 AD) wrote, "There is always something new out of Africa". The same applied in 2014. Just over 12 months ago, no one could have foreseen the global ramifications of the Ebola virus epidemic. A few isolated cases quickly led to epidemic spread in impoverished urban centres of Sierra Leone, Liberia and Guinea that rapidly overwhelmed local health systems. This outbreak has highlighted not only our global vulnerability to epidemics, but also the immense value of traditional strict infection control practices, which when applied have resulted in a marked diminution in the projected size of the epidemic. New technologies have enabled development of novel rapid diagnostics and candidate vaccines which provide enormous hope for future epidemics. ${ }^{10}$

Vaccines against dengue virus and Clostridium difficile are two other examples where there is promise for future advances. However, possession of effective vaccines is not sufficient for control. Infrastructure for delivery needs to be present, and consumers must have confidence in vaccine safety and efficacy. Controlled pathogens can re-emerge when this framework breaks down, as shown by the resurgence of poliomyelitis in war-torn Syria and outbreaks in Pakistan after the murder of vaccine volunteers, and the recent measles outbreak in the US linked to Disneyland in California. The latter shows that electronic media can be a powerful tool for consumer education but also a means to spread misinformation.

The recent dramatic outbreaks of disease caused by Ebola virus, Hendra virus and Middle East respiratory syndrome coronavirus overshadow many advances in management of endemic infections previously thought to be incurable. Hepatitis $C$ infection can now be cleared in a high proportion with antiviral agents, and prospects for a vaccine have never looked better. HIV has now become a long-term chronic viral illness for those infected who have access to newer, better tolerated antiretroviral agents. If longer-acting agents in clinical trials prove effective, further advances may be made, including control of HIV in marginalised groups and more effective prevention. Research into the role of human microbiota in the pathogenesis of both communicable and non-communicable 
diseases may provide further therapeutic advances. Faecal microbiota transplantation has now been proven to be an effective therapy for relapsing $C$. difficile infection and may have other future applications.

These advances have been enabled by the revolution in molecular techniques, including rapid diagnostics such as matrix-assisted laser desorption ionisation time of flight mass spectroscopy, multiplex polymerase chain reaction, and whole-genome sequencing for outbreak investigation. Further advances are expected when they become more widely available in microbiology laboratories. However, technological advances may not always bring benefits. Robotisation of specimen handling is fuelling the creation of remote, 24-hour automated laboratories, with downsizing or closure of on-site hospital laboratories and loss of well trained laboratory scientists. This could see clinicians being given more complex data (eg, on a new obscure organism), without the ability to interpret their significance if there is a lack of available microbiological expertise. Compounding this is the decline in understanding of basic microbiology, infections and antibiotic use in newly graduated junior doctors in Australia. ${ }^{11}$ The end results may be increased inappropriate testing, antibiotic overprescribing and errors in prescribing, which would be counterproductive to our national quality and stewardship aims. This knowledge gap needs to be addressed as a priority by Australian medical schools.

In the field of infectious diseases, every year is replete with surprises. The ASID Annual Scientific Meeting (to be held in 2015 in Auckland on 18-21 March) is a testament to this, presenting both new research and clinical experiences from across the globe. ASID recognises that global strategies to reduce AMR, coupled with the extraordinary advances in molecular diagnostics, are essential for outbreak preparedness and to advance control of endemic pathogens. However, to attempt to see beyond the present to the next 10 years in infectious diseases would be audacious. As Niels Bohr is believed to have said, "prediction is very difficult, especially about the future".

Competing interests: No relevant disclosures.

Provenance: Commissioned; externally peer reviewed.

References are available online at www.mja.com.au. 
1 Gottlieb T, Currie BJ, Looke DF, on behalf of the Executive Council of the Australasian Society for Infectious Diseases. Infectious diseases in Australia - the next decade [editorial]. Med J Aust 2012; 196: 292-293.

2 World Health Organization. Antimicrobial resistance: draft global action plan on antimicrobial resistance. 12 Dec 2014. http://apps.who.int/gb/ebwha/pdf_files/EB136/B136_20-en. pdf (accessed Feb 2015).

3 The White House. National strategy for combating antibioticresistant bacteria. September 2014. http://www.whitehouse. gov/sites/default/files/docs/carb_national_strategy.pdf (accessed Feb 2015).

4 Department of Health, Department for Environment, Food and Rural Affairs. UK five year antimicrobial resistance strategy 2013 to 2018. https: //www.gov.uk/ government/uploads/system/uploads/attachment_data/ file/244058/20130902_UK_5_year_AMR_strategy.pdf (accessed Feb 2015).

5 Shaban R, Cruikshank M, Christiansen K and the Antimicrobial Resistance Standing Committee. National surveillance and reporting of antimicrobial resistance and antibiotic usage for human health in Australia. Canberra: Antimicrobial Resistance Standing Committee, Australian Health Protection Principal Committee, 2013. http://www.safetyandquality.gov.au/ wp-content/uploads/2014/02/National-surveillance-andreporting-of-antimicrobial-resistance-and-antibiotic-usagefor-human-health-in-Australia.pdf (accessed Feb 2015).

6 Australian Commission on Safety and Quality in Health Care. Antimicrobial use and resistance in Australia (AURA) project. http://www.safetyandquality.gov.au/national-priorities/amrand-au-surveillance-project (accessed Feb 2015).

7 Shaban RZ, Simon GI, Trott DJ, et al. Surveillance and reporting of antimicrobial resistance and antibiotic usage in animals and agriculture in Australia. Report to the Department of Agriculture. Canberra: Commonwealth of Australia, University of Adelaide, Griffith University, 2014. http://www.agriculture. gov.au/SiteCollectionDocuments/animal-plant/animalhealth/amria.pdf (accessed Feb 2015).

8 Magill SS, Edwards JR, Bamberg W, et al, for the Emerging Infections Program Healthcare-Associated Infections and Antimicrobial Use Prevalence Survey Team. Multistate pointprevalence survey of health care-associated infections. NEngl J Med 2014; 370: 1198-1208.

9 Mitchell BG, Collignon PJ, McCann R, et al. A major reduction in hospital-onset Staphylococcus aureus bacteremia in Australia -12 years of progress: an observational study. Clin Infect Dis 2014; 59: 969-975.

10 Rampling T, Ewer K, Bowyer G, et al. A monovalent chimpanzee adenovirus Ebola vaccine - preliminary report. NEngl J Med 2015; Jan 28 [Epub ahead of print]. doi: 10.1056/ NEJMoal411627.

11 Chaves NJ, Cheng AC, Runnegar N, et al. Analysis of knowledge and attitude surveys to identify barriers and enablers of appropriate antimicrobial prescribing in three Australian tertiary hospitals. Intern Med J 2014; 44: 568-574. 